\title{
Cognitive Behaviour Therapy in Adolescent with Evolving Anxious Avoidant Personality Disorder
}

\author{
Mahesh $\mathrm{M} \mathrm{M}^{1 *}$, Sahana Madhyastha ${ }^{2}$
}

\section{ABSTRACT}

Theoretical models propose that Personality Disorders (PD) have definite temperamental precursors in childhood (Millon, 1981; Rutter, 1987). ICD 10 Classification diagnostic guidelines also regard manifestations of PD traits in early childhood and adolescence. There is some research evidence suggesting early manifestations of AAPD in childhood and adolescence (Rettew et al., 2003). Severity and persistence of symptoms through early to late adolescence exceeding sub-syndromal levels warrants discussion of presentation and treatment of this case. The patient is a 16 years old boy from first PUC reported complaints of avoiding school earlier and now college because of significant anxiety in interpersonal interaction, fear of being negatively judged, criticized and rejected in social situations and occasional sad mood. These symptoms precipitated five years ago after a love proposal from a girl in school in which he was falsely implicated. Currently also has doubts and fear related to academics. Psychological assessment supports the diagnosis of AAPD. Highly orthodox family environment, indulgent parenting style absence of father, anxious and shy temperament laid the foundation and reinforced negative self-concept. Relaxation training, cognitive restructuring, graded exposure therapy with components of social skills training were carried out (30sessions). Following treatment he is regular to college and is able to challenge his negative cognitions with minor hitches. This case illustrates the need to consider diagnosing and treating AAPD in adolescence when symptoms are severe.

Keywords: CBT, AAPD, Adolescents, negative self concept.

When does anxiety in interpersonal situations become pathological, and what makes it so? Functional impairment is an important element. In personality disorders, there is an assumption that there are clinically significant deficits in both the self and interpersonal relationships. For anxious avoidant personality disorder (AAPD) self-definition encompasses a desire for affiliation

\footnotetext{
${ }^{1}$ Clinical Psychologist, Department of Psychiatry, Kannur Medical College Anjarakandy, Kannur, Kerala

${ }^{2}$ Assistant Professor- Sr. grade, Department of Clinical Psychology, School of Allied Health Sciences, Manipal University, Manipal

*Responding Author (c) 2016 I Mahesh M, S Madhyastha; licensee IJIP. This is an Open Access Research distributed under the terms of the Creative Commons Attribution License (http://creativecommons.org/licenses/by/2.0), which permits unrestricted use, distribution, and reproduction in any Medium, provided the original work is properly cited.
} 
hobbled by a sense of personal inadequacy, and intense fears of interpersonal rejection stemming from a heightened sensitivity to criticism from others is another key feature, leading to social detachment that is perhaps the most obvious clinical feature of AAPD. In broader terms, the feelings of the person suffering AAPD have been described as anxiety and the behaviors as shyness, suggesting overlap with other forms of psychopathology. Historically, one thing that differentiates AAPD from other forms of psychopathology, however, is that AAPD is characterized by isolative interpersonal behaviors combined with a desire to be close to others that is stilted by fears of rejection. Avoidant personality-disordered individuals are characterized by fear of humiliation and rejection that results in social timidity and withdrawal. Avoidant personality can be thought of as spanning a continuum from healthy to pathological, with avoidant personality style on the healthy end and avoidant personality disorder on the pathological end. The typical situation, circumstance, or event that most likely triggers or activates the characteristic maladaptive response of avoidant personality disorder (Othmer \& Othmer, 2002), as noted in behavioral, interpersonal, cognitive, and feeling styles, is "demands for close interpersonal relating and/or social and public appearances." The behavioral style of avoidant personalities is characterized by social withdrawal, shyness, distrustfulness, and aloofness. Behavior and speech are controlled, and individuals appear apprehensive and awkward. Interpersonally, they are rejection sensitive. Even though they desire acceptance by others, they keep distance from others and require unconditional approval before being willing to open up. They guardedly test others to determine who can be trusted to like them. The cognitive style of avoidant can be described as perceptually vigilant - that is, they scan the environment looking for clues of potential threat or acceptance. Their thoughts are often distracted by their hypersensitivity. Not surprisingly, they have low self-esteem because of their devaluation of their own achievements and their overemphasis of their own shortcomings. Their emotional or affective style is marked by a shy and apprehensive quality. Because they are seldom able to attain unconditional approval from others, they routinely experience sadness, loneliness, and tenseness. Individual with a self-view was negative and another view that vacillates between positive and negative exhibit a composite preoccupied and fearful style of attachment. Their avoidance is based on the desire to be liked and accepted by others while fearing rejection and abandonment. The preoccupied-fearful attachment style is common in adults with avoidant personality disorder (Lyddon \& Sherry, 2001). The optimal criterion for this disorder is "avoids occupational activities that involve significant interpersonal contact fearing criticism, disapproval, or rejection.” The prevalence of personality disorders in children and adolescents is still a point of debate, but there is cumulative evidence that personality disorders can be reliably diagnosed in adolescents (Chanen \& McCutcheon, 2008; Grilo et al., 1998; Johnson et al., 2000; Westen, Shedler, Durett, Glass, \& Martens, 2003).

Theoretical models propose that that Personality Disorders (PD) have definite temperamental precursors in childhood (Millon, 1981; Rutter, 1987). ICD 10 Classification diagnostic guidelines also regard manifestations of PD traits in early childhood and adolescence. There is some research evidence suggesting early manifestations of AAPD in childhood and adolescence 
(Rettew et al., 2003). Severity and persistence of symptoms through early to late adolescence exceeding sub-syndromal levels warrants discussion of presentation and treatment of this case

\section{Case Summary:}

This case illustrates the course of treatment of a 16 years old Muslim male named TM, who was a PUC student in Karnataka. He was referred for diagnostic psychometry for clarifying the diagnosis of Anxious Avoidant Personality Disorder vs. Anxiety Not Otherwise Specified. and psychological management The diagnostic psychometry results pointed towards a provisional diagnosis of AAPD and patient was continued for the treatment for managing his problems. Owing to his complaints, the client had stopped attending college and avoided most social interactions. He had sought psychiatric treatment earlier but no improvement was seen. However, no psychological therapy has been sought until now. The client presented with complaints of avoiding school earlier and now college because of significant anxiety in interpersonal interaction, fear of being negatively judged, criticized and rejected in social situations and occasional sad mood. These symptoms precipitated five years ago after a love proposal from a girl in school in which he was falsely implicated. He also currently has fainting episodes lasting for 10- 15 minutes accompanied by palpitations, tremors, dry mouth, and difficulty in breathing. Doubts and fears related to academics are his other concerns.

\section{Case History:}

Patient is a first born child, currently studying in first PUC, from MSES extended family. The patient was apparently normal till the age of 12 years $\left(6^{\text {th }}\right.$ class), when he first started complaining of stomach ache and head ache, and started being absent from school. The mother noticed that on hearing any sensitive news, or feeling burdened by school work, he would experience distress and occasionally faint. He would be worried whether he would top the school or not this thousand this worry would make him extremely tensed and soon it would turned into fear, which was associated with palpitations, tremors, dry mouth, and difficulty in breathing.. Later, he would be told that he had fainted for about 10 - 15 minutes. Such episodes of giddiness and falls lasted for 10- 15 minutes and on waking he would not be aware of this episode. The occurrence of such episodes and fearful anticipation of future episodes held by the client were one of the reasons for him to eventually discontinue regular schooling in VIII class and opt for home schooling till the end of high school. The other predominant reason which also acts as a notable precursor of the current symptom is an event in VIII class which involved a girl who was a close friend of his, who made a love proposal to him and he rejected the same. Following this, angered by his rejection, she falsely implicated him and complained to her cousin sister saying that he was troubling her. The cousin took up this issue with him; as a result he got tensed and had fainting episodes. His and his close friend's family members became aware of this issue and this caused a lot of embarrassment to him. Later, he became fearful that this news would have spread among his friends and school and started feeling that they were making fun of him and thought of him as morally bad individual. Thereafter, owing to the fear of being criticized and rejected he stopped going to school and continued studies at home. In SSLC exam, patient 
obtained 76.8\%and then decided to attend regular college for Pre-university study. During a lecture where he faced difficulty in comprehending the concepts being taught, he fainted and fell down. When he returned to class after recovering, he assumed that all his new friends were laughing at him. Following this episode, he has not spoken to any of his friends and he stopped going to college. The client says that he has no friends as he doesn't make friends because he is scared that he won't be liked.

He also has academic concerns, such as worries about not being able to study effectively and do well in exams. Whatever the criticism towards him he accepts without opposition and worrying about it. Patient first consulted a psychiatrist in 2010 where he was started on T. Torvate Chrono 300mg, T. Rispond 2mg, T. rexipra 5mg, T. Zapiz 0.25mg and t. beta cap Cr 10mg.

\section{Temperamental history:}

As reported by the parents he was a shy, but well- mannered child, who would not interact much with non-family members, and mostly keep to himself. Even with friends He would not talk much and would be a silent listener most of the time. He would also try to avoid social functions as much as possible. Parents also reported that during stressful times he would get tensed easily and would find it difficult to cope with it. However, he is expressive with parents and attached to them. His energy levels were slightly low and threshold of responsiveness was slightly low. Quality of mood was mostly anxious and behaviorally he was withdrawn in nature. Impression was that he had shy and anxious temperament in childhood.

\section{Early childhood and Home atmosphere:}

Patient is the elder child and is living with his mother in a joined family. During that time his father's job was in abroad. The mother was reported of having anxious traits and she is very much involved and protective towards the patient. Family atmosphere was highly orthodox and strictly followed the moral values.

In this context, it deems appropriate to comment on his moral attitude. He holds firmly to his concepts about good and bad behaviour. If he observes any violation of moral code, even by people remotely related to him, he gets highly distressed. For instance, if boys and girls are seen interacting in a non-platonic fashion, he gets upset that that it's a bad behavior and has strong wish to advise them against it

\section{Assessment:}

The patient has produced a valid test record that should ordinarily provide reliable information about his personality functioning. On Rorschach the findings indicate that patient has an avoidant style of information processing. His emotional reservedness resulting into emotional inhibition poses difficulties in interpersonal relations. Also, he compares himself unfavorably to other people and consequently suffers from low self-esteem and limited self-confidence. The patient gives evidence of limited capacity to form close attachments to other people and engages 
in superficial relations with most people. He is also likely to avoid new and challenging situations and be limiting himself to familiar surrounds and people who are likely to accept him. The finding on Rorschach aligns with 16 PF findings in which his anxious and avoidant traits are evident. The IPDE also helps to speculate the presence of anxious avoidant traits though a diagnosis cannot be confirmed because of his age. As per IPDE findings, the presence of anankastic traits also can be speculated. There is also some evidence in Rorschach, where there is an indication of logical inflexibility because of which he tends strongly cling to previously held beliefs. He is not likely to change his beliefs even if contrary evidence is present. However there is no evidence for anankastic traits in 16 PF. In State Trait Anxiety Questionnaire patent got a score of 43 in state anxiety and 61 in trait anxiety level. In Leibowitz Social anxiety Scale he got a score of 43 in anxiety level and 48 in avoidance.

Therapeutic Formulation: The patient is a 16 years old boy studying in first PUC, living in a joint family, temperamentally shy and anxious and being the child of highly orthodox Muslim family, indulgent parenting style and lack of father figure in childhood, his family environment and certain personal events involving peer rejection experiences laid the foundation and then reinforced his negative view of himself. This negative self-view is typically activated in interpersonal situations where he perceives rejection. In order to function in the world, he has established rigid assumptions for himself: i.e., "I am bad; people will reject me," .To operationalizes his assumptions, he has developed the following behavioral compensatory strategies: submission, avoidance, and acquiesce.

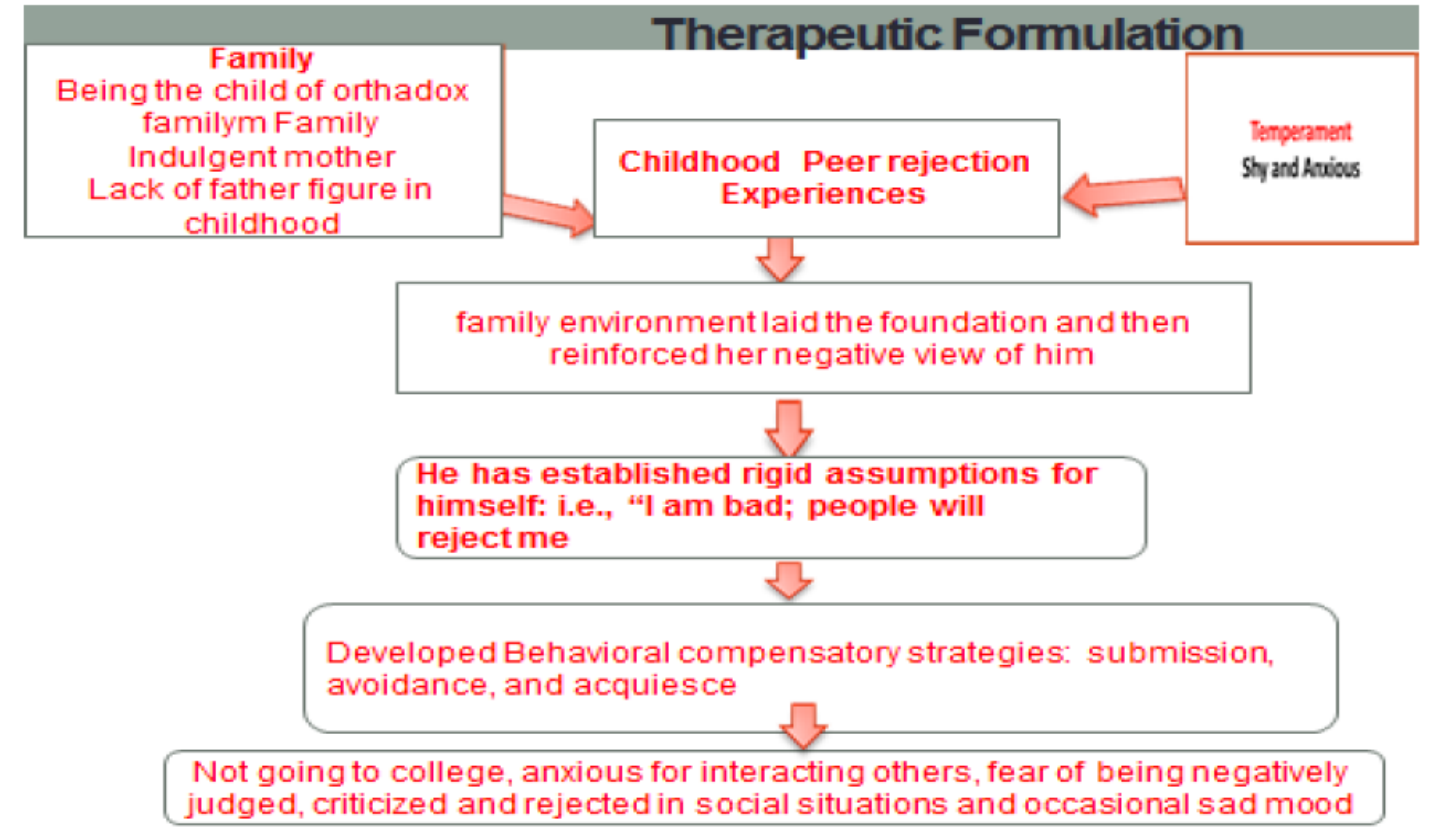

Rationale for intervention: Cognitive Behavior therapy has been found to be effective in people with AAPD. It helps to test the negative automatic thoughts and the underlying assumptions which can help them to counter self-criticism, negative predications, maladaptive assumptions and misevaluation of other's reactions. Cognitive restructuring and Behavioral 
interventions in the form of exposures, role playing and social skill training have also been employed in order to help such individuals. Behavioral experiments were designed so that the patient's beliefs could be tested.

Treatment and discussion: This treatment program lasted a total of 30 sessions followed by a 1-month follow-up session. The program integrated CBT techniques- thought diary, thought challenging, Socratic questioning, graded exposure along with JPMR and behavioural experiments. The main active components of the treatment were:

Relaxation training: In view of his significant autonomic arousal symptoms JPMR was initiated. The patient was explained the rationale of Jacobson's progressive relaxation techniques (tensing and relaxing different muscle parts of the body) and five sessions of relaxation training were given. The patient was asked to practice the same daily at home. Relaxation was presented as a skill to be learned during several applied stages, with continued practice at least once a day to help reduce his general tension level.

Cognitive Restructuring: According to Beck and Freeman (1990), individuals with avoidant personality are fearful of initiating relationships as well as of responding to others' attempts to relate to them because of their overriding belief that they will be rejected. For them, such rejection is unbearable, so they engage in social avoidance. Furthermore, they engage in cognitive and emotional avoidance by not thinking about things that could cause them to feel dysphoric. Because of their low tolerance for dysphoria, they further distract themselves from their negative cognitions. Underlying these avoidance patterns are maladaptive schemas or longstanding dysfunctional beliefs about self and others. Schemas about self - include themes of being different, inadequate, defective, and unlikable. Schemas about others involve themes of uncaring and rejection. These individuals are likely to predict and interpret the rejection as caused solely by their personal deficiencies. This prediction of rejection results in dysphoria. Finally, avoidant individuals do not have internal criteria to judge themselves in a positive manner. Thus, they must rely on their perception. They tend to misread a neutral or positive reaction as negative, which further compounds their rejection sensitivity and social emotional and cognitive avoidance. In short, they hold negative schemas, which lead them to avoid solution where they could interact with others. They also avoid tasks that could engender uncomfortable feelings and avoid thinking about matters which produce dysphoria. Because of their low tolerance for discomfort, they utilize distractions, excuse making, and rationalizations when they begin to feel sad or anxious.

Thought diary, challenging the thoughts and Socratic questioning were used to replace his dysfunctional thoughts by healthy cognitions and stop college refusal. He was educated about cognitive distortions and the common cognitive errors of him. He was then taught how to maintain the thought diary in order to identify the specific negative automatic thoughts in specific interpersonal and social situations which led to increase in distress and avoidance of 
situations. After checking his understanding about these concepts, he was taught how to transform the same into a thought diary. For restructuring the negative cognitions Socratic questioning and thought challenging were used. In this part of the treatment, the therapist explained how thoughts are also associated with his avoidance and social withdrawal.

Role play and Graded exposure therapy: were used for reducing his anxiety in social situations and improving social skills. Initially assess the subjective units of distress by using Leibowitz social anxiety rating scale. Based on the rating selected the least anxiety arousing situation in a graded manner for exposure therapy Before giving direct exposure, modeling and role play were done. Behavioural experiments were done for testing the validity of his thinking of what others thought about him. The successful treatment outcome of Evolving Anxious avoidant Personality disorder using cognitive-behavioral strategies was maintained at first month follow-up but showed some recurrence of symptoms such as avoidance of college at $15^{\text {th }}$ day. But the client was able to restart college after a sessions through phone. Relapse remains a significant problem in AAPD and may be regular follow up reduce the relapse. Dovetailing treatment into relapse prevention could produce a more seamless break between treatment and follow-up, but would require a gradual fading of therapy and spacing of meetings.

Phase III (Termination): Session was temporarily terminated and patient was under regular follow up.

\section{OUTCOME OF THERAPY:}

- Patient‘s avoidant behaviour was reduced and he started to going college over a one month period after we started therapy.

- Anxiety was rated in different times, shows significant improvement (STAI).

- On the Leibowitz social anxiety scale', patient obtained the score of 43 on anxiety, and 48 on avoidance before the therapy; and 5 on anxiety, and 12 on avoidance after the therapy, reflecting a significant improvement in the patient with regard to avoidance and feeling of fearfulness in interpersonal situations.

- Patient reported that now he does not face any difficulty in making requests, denying the unreasonable requests by other people, answering in the class.

- He was able to perform well in the last public exam (First PUC).

- There was a drastic improvement in his eye contact, posture, audibility and gestures in later sessions.

- The patient was able to challenge and reattribute his faulty cognitions independently, by the end of the sessions. 


\section{Patient's social Anxiety rating in Leibowitz social anxiety scale}

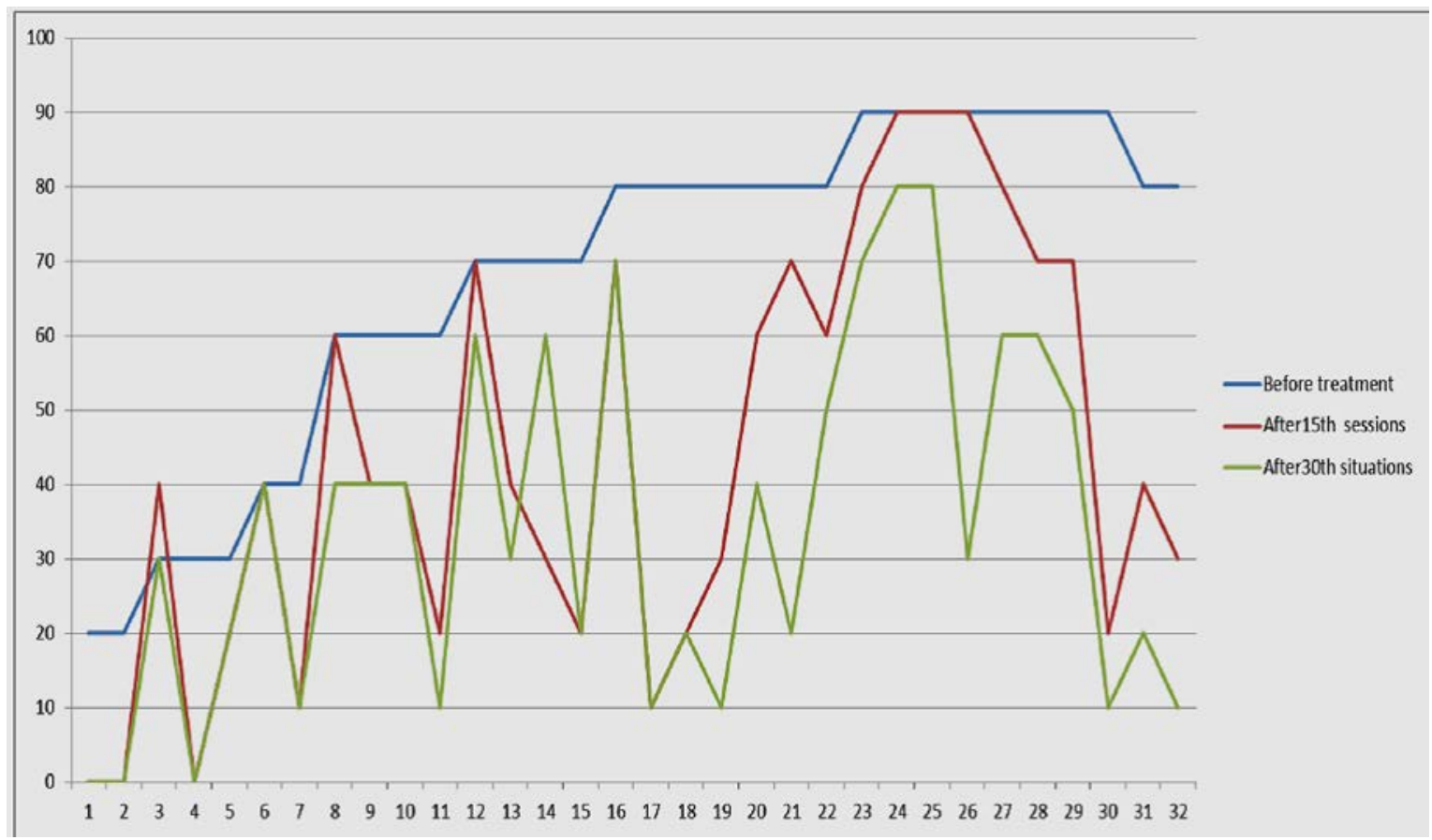

Complicating factors: Obstacles faced during therapy were that the patient had seen any couples or boy/girl together became anxious and dull. We reframed his setback as a reactivation of his schema due to an unfortunate incident coupled with his over moralistic attitude as an opportunity to practice responding to negative automatic thoughts and solidifying a new, healthier belief. Anxiety as rated in between two times shows significant improvement in different areas of interpersonal functioning.

Outcome: Patients avoidant behaviour was reduced and he started to going college over a one month period after we started therapy. He remains in therapy to work on feminine character, improving social skills and his self-image.

\section{CONCLUSION}

Usually avoiding behaviour of the evolving AAPD adolescents were not notice as a problem rather it is considered as shyness of the individual. All diagnostic classificatory systems diagnose AAPD after 18 years. The uniqueness of this case is the severity of the AAPD traits starting from early adolescence which warrants a diagnosis before reaching adulthood, sometimes as early as childhood. Because of his avoidant personality client was avoiding school earlier and now college and other social functions and social situations. Adolescence is the period when selfidentity forms. So identification and the effective treatment of possible personality disorders are most important among adolescents. Hence, classificatory systems should evolve to include such severe cases for consideration towards diagnosis of personality disorders to facilitate prompt and effective treatment. 


\section{REFERENCES}

Chanen A M \& McCutcheon L k (2008) complex case Personality disorder in adolescence: The diagnosis that dare not speak its name Personality and Mental Health Volume 2, Issue 1

Grilo, C. M., McGlashan, T. H. \& Oldham, J. M. (1998) Course and stability of personality disorders. Journal of Practical Psychiatry and Behavioral Health, 4, 61-75

Johnson, J. G., Cohen, P., Kasen S., et al (2000) Age-related change in personality disorder trait levels between early adolescence and adulthood: a community-based longitudinal study. Acta Psychiatrica Scandinavica, 102, 265 -275.

Lyddon. W J \& Sherry A (2001) Developmental Personality Styles: An Attachment Theory Conceptualization of Personality Disorders. Journal of Counseling \& Development Volume 79, Issue 4.

Millon, T. (1981). Disorders of personality: DSM-III, Axis II. New York: Wiley-Interscience.

Othmer, E., \& Othmer, S. C. (2002). The clirzicul interview using DSM-IV-TR. Volume I: Fundamentals. Washington, D.C. \& London: American Psychiatric Press.

Rettew D C, Althoff R R, Dumenci, L, Ayer, L \& Hudziak, J J (2003) Latent Profiles of Temperament and Their Relations to Psychopathology and Wellness. Child and adolescent psychiatry. March 2008Volume 47, Issue 3, Pages 273-281

Rutter M. (1987) Parental mental disorder as a psychiatric risk factor. In: Hales R, Frances A, editors.American Psychiatric Association annual review. Vol. 6. American Psychiatric Press, Inc.; Washington, DC.

Westen, D., Shedler, J., Durrett, C., Glass, S., \& Martens, A. (2003). Personality diagnosis in adolescence: DSM-IV Axis II diagnoses and an empirically derived alternative. American Journal of Psychiatry, 160, 952-966. 